\title{
Nucleotide sequence of the structural gene encoding a 2-haloalkanoic acid dehalogenase of Pseudomonas putida strain AJ1 and purification of the encoded protein
}

\author{
David H. A. Jones, ${ }^{1}$ Peter T. Barth, ${ }^{2}$ David Byrom ${ }^{3}$ and Christopher M. Thomas ${ }^{1 *}$ \\ ${ }^{1}$ School of Biological Sciences, University of Birmingham, PO Box 363, Birmingham B15 2TT, UK \\ ${ }^{2}$ Department of Biotechnology, ICI Pharmaceuticals, Alderley Park, Cheshire SK10 4TG, UK \\ ${ }^{3}$ Biological Products, ICI plc, PO Box 1, Billingham, Cleveland TS23 ILD, UK
}

(Received 3 October 1991; revised 6 January 1992; accepted 20 January 1992)

\begin{abstract}
The nucleotide sequence of a gene encoding an L-2-haloalkanoic acid halidohydrolase from Pseudomonas putida strain AJ1 was determined. The ORF ( $\mathrm{hadL}$ ) codes for a polypeptide of 227 amino acids $\left(M_{\mathrm{r}} 25687\right)$ which has significant homology to two other L-2-haloalkanoic acid halidohydrolases of Pseudomonas sp., DehcI and DehcII; these show $38 \%$ and $51 \%$ amino acid identity respectively to HadL. All three enzymes produce products of an opposite optical configuration to that of the substrates. Comparison of the three sequences shows several highly conserved motifs which indicate the possible position of the enzyme active site. The enzyme was purified to homogeneity and appears to exist as a tetramer.
\end{abstract}

\section{Introduction}

Halogenated aliphatic hydrocarbons are a significant group of environmental pollutants and dehalogenation is an important step in their degradation and mineralization. A number of micro-organisms have been isolated which are capable of degrading such compounds (Ghosal et al., 1985; Chaudhry \& Chapalamadugu, 1991). Most studies on the genetic basis of such degradation have concentrated on the haloalkanes (Janssen et al., 1989; La Roche \& Leisinger, 1990) and haloalkanoic acids.

Bacteria with haloalkanoic acid halidohydrolases appear to be readily isolated from the environment (Hardman \& Slater, 1981) and include several strains of Pseudomonas spp. (Goldman et al., 1968; Little \& Williams, 1971; Slater et al., 1979; Motosugi et al., 1982; Klages et al., 1983; Tsang et al., 1988). These enzymes act by hydrolysing the haloacid (each enzyme is capable of degrading a range of substrates) to yield inorganic chloride. The optical configuration of the products

* Author for correspondence. Tel. (021) 414 5903; fax (021) 4145925.

Abbreviation: MCPA, monochloropropionic acid.

The nucleotide sequence data in this paper have been submitted to GenBank and have been assigned the accession number M81841. appears either to be inverted or to be maintained and mechanisms for reactions have been suggested by Weightman et al. (1982).

Such bacteria often appear to produce more than one dehalogenase enzyme, specific for either a single stereoisomer of the chemical or active against both isomers (Weightman et al., 1982; Leigh et al., 1988). Some strains appear to encode isofunctional dehalogenase enzymes (Schneider et al., 1991), suggesting that differential regulation of the coding genes or different mechanisms of reaction may optimize the degradative activity.

Pseudomonas putida strain AJ1 was isolated from a soil sample which had previously been exposed to 2-monochloropropionic acid (MCPA; ICI Biological Products, Billingham, UK), a chemical used in the manufacture of a number of herbicides. AJl appeared to produce two enzymes, each responsible for the degradation of a single stereoisomer of MCPA. The enzyme with D-MCPA dehalogenase activity (HadD) was purified and shown to exist as a tetramer which is able to degrade a range of short-chain D-2-halocarboxylic acids (Smith et al., 1990). The $\mathrm{N}$-terminal sequence was determined and used to design a single oligonucleotide probe which was used to probe a gene library of AJ1 DNA. A single DNA fragment of $10 \mathrm{~kb}$ was isolated (in plasmid pTB281; see Fig. 1) which encoded the enzymes for the degradation of 
both D-MCPA and L-MCPA (HadD and HadL respectively; Barth et al., 1992). In each case the MCPA is hydrolysed to yield lactate with the release of chloride ions (ICI Biological Products, personal communication). The hadD gene was sequenced and shown to encode a polypeptide of 300 amino acids (Barth et al., 1992). This appears to show no homology to two genes recently cloned from $P$. putida strain CBS3, dehcI and dehcII, products of which catalyse the reaction of L-2-monochloropropionic acid to D-lactate (Schneider $e$ t al., 1991).

In this paper we report the DNA sequence of hadL and describe the purification of the encoded protein.

\section{Methods}

Bacterial strains and plasmids. DNA manipulations were performed in Escherichia coli JM83 (Yanisch-Perron et al., 1985). The plasmid pUC18 was used as a vector for DNA sequencing (Yanisch-Perron et al., 1985); pTB281 contains the $10 \mathrm{~kb}$ fragment of AJ1 DNA (Fig. 1); expression vector pGBT30, provided by Dr G. Jagura-Burdzy, contains a pMBl replicon, lacl ${ }^{9}$, and the tac promoter upstream of a pUC18 multiple cloning site (Jagura-Burdzy et al., 1991). Plasmids constructed during the course of this work are shown in Fig. 1. Cells were grown at $37^{\circ} \mathrm{C}$ in L-broth or on L-agar, supplemented when necessary with penicillin ( $100 \mu \mathrm{g} \mathrm{ml}^{-1}$ in $\mathrm{LB}, 300 \mu \mathrm{g} \mathrm{m}^{-1}$ in LA). For induction of the tac promoter IPTG was added to $0.5 \mathrm{~mm} 3 \mathrm{~h}$ prior to harvesting the cells.

DNA manipulations. Plasmid DNA was isolated by the alkaline-SDS method of Birnboim \& Doly (1979). Restriction enzymes and other DNA-modifying enzymes were purchased from Northumbria Biologicals or Bethesda Research Laboratories and used according to the manufacturer's instructions. Agarose gel electrophoresis was carried out by standard procedures (Sambrook et al., 1989). DNA fragments for cloning were isolated by electrophoresis on a $1 \%(w / v)$ TAE agarose gel (Sambrook et al., 1989) and purified using the Gene-clean kit from Biol01.

DNA sequence analysis. DNA sequencing by the chain-termination method (Sanger et al., 1977) was carried out on double-stranded plasmid DNA template using the Sequenase kit supplied by United States Biochemical Corp. (USB). Template DNA was purified by $\mathrm{CsCl} /$ ethidium bromide density-gradient centrifugation. Primers were either sequencing primer or reverse sequencing primer from USB, or synthetic 16-mer oligonucleotides synthesized by Alta Bioscience. Sequencing reactions were resolved by electrophoresis on $8 \%(w / v)$ polyacrylamide urea gels.

Nucleotide and amino acid sequences were analysed using the UWGCG programs (Devereux et al., 1984).

Protein purification. Bacteria containing the overexpressing plasmid pHAD13 (Fig. 1) were grown overnight in $500 \mathrm{ml} \mathrm{L-broth}$. Cultures were then diluted 1 in 2 and IPTG added to $0.5 \mathrm{mM}$. After a further $3 \mathrm{~h}$ the cells were harvested, resuspended in sonication buffer $(20 \mathrm{~mm}$ Tris/HCl pH 8.0, $10 \mathrm{~mm}-\beta$-mercaptoethanol, $10 \%$, v/v, glycerol, $1 \mathrm{~mm}$ phenylmethylsulphonyl fluoride, $1 \mathrm{~mm}-\mathrm{EDTA})$, and sonicated over $10 \mathrm{~min}$ ( $30 \mathrm{~s}$ bursts, $30 \mathrm{~s}$ cooling periods). The sonicate was centrifuged at 40000 r.p.m. for $1 \mathrm{~h}$, and the supernatant was removed and stored at $-70^{\circ} \mathrm{C}$. Extract was applied to a DEAE-Sephacel anion-exchange column equilibrated with $0.05 \mathrm{mM}-\mathrm{Tris} / \mathrm{HCl} \mathrm{pH} 7.0$ and $0.25 \mathrm{M}-\mathrm{NaCl}$. Protein was eluted in the same buffer. Samples were then applied to an
Anagel-TSK G3000SW $7.5 \mathrm{~mm} \times 60 \mathrm{~cm}$ gel filtration column equilibrated with $25 \mathrm{~mm}$-potassium phosphate buffer $(\mathrm{pH} 7.4)$, and run on a modular Gilson HPLC system controlled by an IBM PC. Protein samples were analysed on a standard SDS-polyacrylamide gel (Laemmli, 1970) and stained with Coomassie brilliant blue R250. When necessary, proteins were concentrated either by membrane filtration using a Filtron Microsep centrifugal microconcentrator (Flowgen), or by precipitation with 4 vols methanol/acetone $(1: 1, v / v)$.

Qualitative assay of dehalogenase activity. Dehalogenase activity of protein samples in a non-denaturing gel was detected by immersion in a solution of 50 mM-MCPA followed by detection of released $\mathrm{Cl}^{-}$ions by precipitation of silver chloride. Duplicate samples were electrophoresed on a standard protein gel (Laemmli, 1970) except that 0.1 mMDTT was used in place of $10 \%(w / v)$ SDS, and all buffers were Tris/ $\mathrm{H}_{2} \mathrm{SO}_{4}$. Samples were not boiled prior to loading, contained no bromophenol blue or other dye, and were electrophoresed at $4^{\circ} \mathrm{C}$ until marker dye in an adjacent well had reached the bottom of the gel. Half the gel was stained with Coomassie brilliant blue R250. The other half was immersed in $50 \mathrm{~mm}$-DL-MCPA in $0.2 \mathrm{M}$-Tris/ $\mathrm{H}_{2} \mathrm{SO}_{4} \mathrm{pH} 8.0$ at room temperature for $40 \mathrm{~min}$. It was then washed thoroughly with water and then placed in $0.1 \mathrm{M}-\mathrm{AgNO}_{3}$ for a few minutes until a precipitate of $\mathrm{AgCl}_{2}$ became visible on the gel. This demonstrates the presence of $\mathrm{Cl}^{-}$ions, which correspond to the position of any protein in the gel that is able to dechlorinate the MCPA. The gel was fixed in $5 \%$ $(v / v)$ acetic acid for $15 \mathrm{~min}$ and then vacuum-dried.

Quantitative assay of dehalogenase activity. Release of halide ions was detected by titration against silver nitrate on a Mettler DL21 automatic titrator: $1 \mathrm{ml}$ of a buffered solution of $100 \mathrm{~mm}$-substrate was titrated with $10 \mathrm{ml} 10 \mathrm{~mm}-\mathrm{AgNO}_{3}$ and the end-point determined by potentiometric analysis.

Determination of the optical configuration of lactate product. The presence of $\mathrm{D}$ - or L-lactate was assayed by the principle described by Noll (1984). Assay mixtures contained $810 \mu \mathrm{l} \mathrm{H}_{2} \mathrm{O}, 30 \mu \mathrm{l} 50 \mathrm{mM}-\mathrm{NAD}$, $110 \mu \mathrm{l} 1 \mathrm{M}$-glycine/ $\mathrm{NaOH} \mathrm{pH} 10 \cdot 0,20 \mu \mathrm{l} \mathrm{DL}-\mathrm{MCPA} \mathrm{pH} 7 \cdot 2,30 \mathrm{U}$ of either Leuconostoc mesenteroides D-lactate dehydrogenase (Sigma) or rabbit L-lactate dehydrogenase (Boehringer Mannheim), and an aliquot of $\mathrm{HadL}$. The reaction proceeded at $25^{\circ} \mathrm{C}$ and the absorbance was measured at $340 \mathrm{~nm}$ in a Pye Unicam SP1800 spectrophotometer.

Determination of $\mathrm{N}$-terminal amino acid sequence. Homogeneous samples of protein were analysed on an Applied Biosystems protein sequencer.

\section{Results}

\section{Physical mapping of the hadL gene}

The structural gene hadL was known to lie downstream of hadD on a $10 \mathrm{~kb}$ fragment of DNA cloned from Pseudomonas putida strain $\mathrm{AJ}$, and was suspected to be transcribed in the same direction as hadD (Fig. 1; Barth et al., 1992).

The $2.9 \mathrm{~kb}$ BamHI fragment containing most of hadD and a large downstream portion of DNA was subcloned into the high-copy-number vector pUC18 (Fig. 1). This $2.9 \mathrm{~kb}$ fragment was then inserted into the expression vector pGBT30 downstream of the $t a c$ promoter. Upon SDS-PAGE analysis, a protein of $M_{\mathrm{r}} 26000$ was 
pTB281 insert

(10 kb fragment of AJI DNA)

Sequencing strategy

pHAD $9.2(2.9 \mathrm{~kb} \mathrm{BamHl}$ fragment of pTB281 in pUC18) pHADII $(2.9 \mathrm{~kb}$ BamHI fragment of pTB281 in pGBT30)

pHADl $3(0.85 \mathrm{~kb}$ Sst I-SstII fragment in pGBT30)

pHAD14 (0.9 kb Sst I-EcoRV fragment in pGBT30)
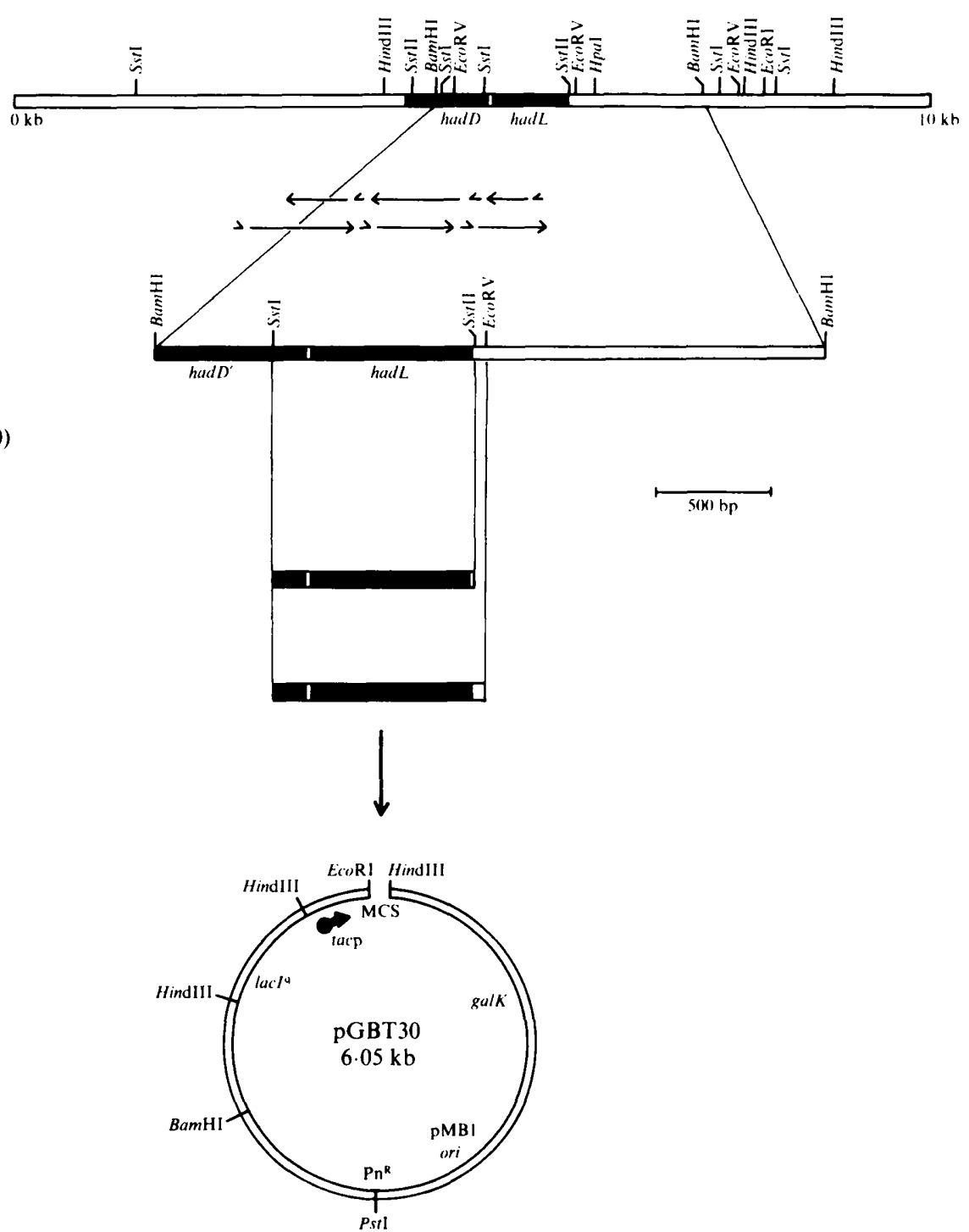

Fig. 1. Cloning of $h a d L$ into an expression vector. The dehalogenase genes were cloned on a $10 \mathrm{~kb}$ fragment into the IncQ plasmid vector pTB244 to give pTB281 (Barth et al., 1992). The $2.9 \mathrm{~kb} \mathrm{BamHI}$ fragment was first cloned into the high-copy-number vector pUC18, and three DNA fragments containing hadL were then cloned downstream of the tac promoter in the multiple cloning site of pGBT30. The sequencing strategy employed for the sequencing of hadL is also shown.

observed in cultures induced with IPTG. A $0.85 \mathrm{~kb}$ Sst ISst II fragment and a $0.9 \mathrm{~kb}$ Sst I-EcoRV fragment were also cloned into pGBT30 (pHAD13 and pHAD14; Fig. 1). The Sst I site lies very close to the end of hadD, and it was hoped that one or both fragments would contain the intact putative hadL gene. SDS-PAGE analysis of bacteria containing these plasmids demonstrated the presence of a protein of a size identical to that previously seen from the larger DNA fragment (Fig. 2). This demonstrated that an intact gene lay before the SstII site as the $0.85 \mathrm{~kb}$ fragment does not produce a truncated protein. These plasmids also produced a large amount of the $M_{\mathrm{r}} 26000$ protein $(10-15 \%$ of total protein) and so could be used as a source for subsequent purification of the protein.

\section{Purification and identification of HadL}

The majority of the $M_{\mathrm{r}} 26000$ protein produced from pHAD 13 appeared to be in soluble form, present mainly in the supernatant (fraction I) after sonication, although some remained in the cell debris. Upon anion-exchange chromatography at $\mathrm{pH} 7.0$ the protein eluted very slowly at $0.25 \mathrm{M}-\mathrm{NaCl}$. At this salt concentration most cellular proteins eluted first, leaving the putative $\mathrm{HadL}$, an 


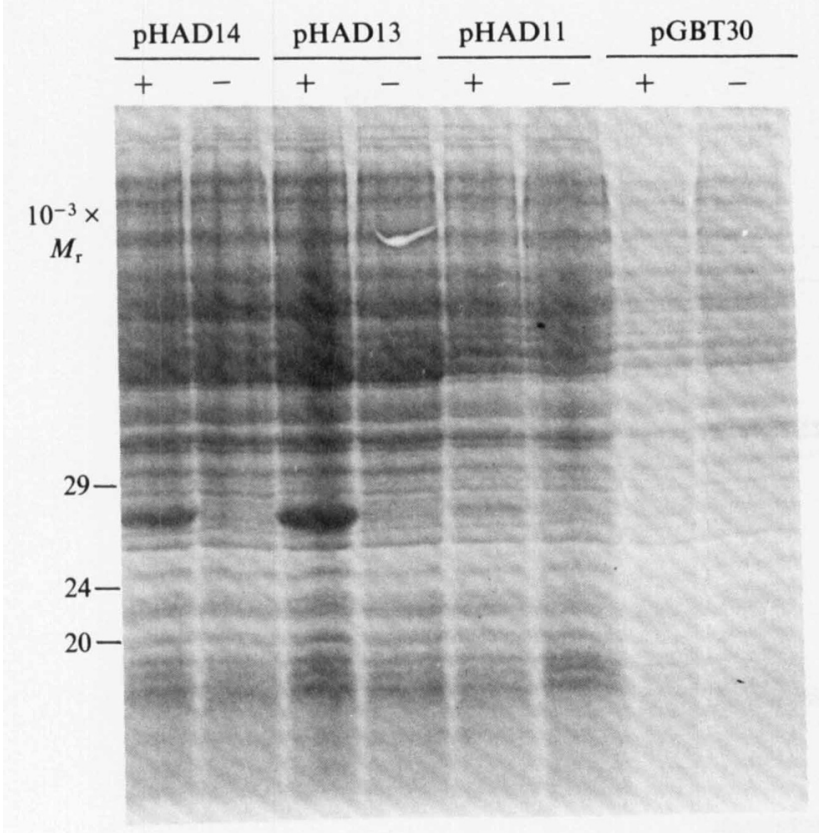

Fig. 2. Induced (+) and uninduced (-) E. coli strains containing the control plasmid pGBT 30 with pHAD11, pHAD13 and pHAD14. The overexpressed polypeptide running at $M_{\mathrm{r}} 26000$ is the putative $\mathrm{HadL}$. It can be seen that pHAD13 does not produce a truncated protein.

unidentified protein and a low background of protein eluting later. HadL was estimated to be approximately $60 \%$ of total protein after this step (fraction II).

To purify HadL further, the eluent from the anionexchange column was passed down an HPLC gel filtration column, and fractions obtained in which HadL was the only protein detected by the HPLC UV monitor (fraction III). HPLC gel filtration elution times were calibrated with a set of protein standards. From this it appeared that HadL eluted predominantly as a protein of $M_{\mathrm{r}} 79000$, with a smaller peak at $M_{\mathrm{r}} 21000$, suggesting that the protein exists as a tetramer. When the larger species was analysed by SDS-PAGE it ran with an apparent $M_{\mathrm{r}}$ of 26000 . Under some conditions homogeneous samples of the protein also appeared to elute as a protein of $M_{\mathrm{r}} 52000$, presumably the dimer. Furthermore, if the sample was boiled prior to gel filtration the $M_{\mathrm{r}} 21000$ protein was the only species present. It thus seems likely that HadL exists as a tetramer (as indeed does HadD; Smith et al., 1990), although the data do not completely rule out the possibility that it is a trimer.

The first 30 amino acids of the protein in fraction III were determined and were found to correspond precisely with the predicted sequence shown in Fig. 3, except residues at position 2 (Lys), which was unclear, and position 25 (Cys), which was unidentified.

Fractions II and III were tested on a non-denaturing protein gel for dehalogenase activity. After soaking the gel in MCPA and then adding silver nitrate, a silver chloride precipitate appeared almost immediately as a single band on the gel in the fraction II sample; no activity was dectectable from fraction III. However, staining duplicate lanes with Coomassie blue showed that the band from fraction II with dehalogenating activity ran at precisely the same position as the purified protein obtained from the HPLC purification. The protein sequencing data described above established that this protein was encoded by the gene downstream of hadD. The dechlorination test therefore confirms that this gene encodes $\mathrm{HadL}$, although gel filtration under the conditions used results in loss of most of the enzyme activity.

To determine whether HadL hydrolysed L-MCPA to L-lactate or D-lactate the reaction was linked to either L- or D-lactate dehydrogenase. Only in the presence of D-lactate dehydrogenase and $\mathrm{HadL}$ was NAD reduced to NADH; no activity was apparent with L-lactate dehydrogenase. This demonstrates that $\mathrm{HadL}$ degrades L-MCPA to D-lactate.

\section{Nucleotide sequence of hadL}

The strategy employed to sequence the region encoding hadL is shown in Fig. 1. The region contained a single ORF of 681 bp (Fig. 3) starting from an ATG initiation codon 23 bp downstream of the stop codon of the hadD ORF. The predicted amino acid sequence from this start is identical to the $\mathrm{N}$-terminal amino acid sequence obtained from HadL, demonstrating that this is the translational start. The hadL ORF has a G $+C$ content of $52 \mathrm{~mol} \%$, which is lower than that of the P. putida chromosome (60-63\%; Normore, 1976) although in the third position of each codon this figure is $61 \%$. This bias is reflected in the codon usage, with codons containing $\mathrm{A}$ and $T$ present at a higher frequency than is normally found in Pseudomonas sp. (Wada et al., 1991). The ORF terminates $40 \mathrm{bp}$ before the SstII site, known from the studies described earlier to lie after the structural gene.

Upstream of the start codon is a good ribosomebinding site (AAGGAA), but no consensus promoter sequence is apparent. Furthermore, insertion of a transposon immediately upstream of hadD in pTB281 (which contains the $10 \mathrm{~kb}$ fragment of AJ1 DNA; Fig. 1) abolishes expression of hadL (data not shown), suggesting that $h a d D$ and $h a d L$ are cotranscribed from a promoter upstream of hadD. Approximately $240 \mathrm{bp}$ downstream of hadL is a potential transcriptional terminator (Platt, 1986) which contains a stem of seven perfectly matched bases and a loop of nine bases, and is followed by an AT-rich region. Expression studies currently in hand suggest this is indeed a transcriptional 
10

30

50

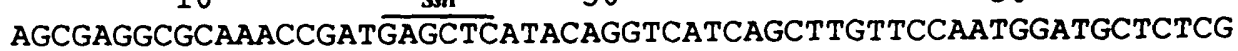
TCGCTCCGCGTTTGGCTACTCGAGTATGTCCAGTAGTCGAACAAGGTTACCTACGAGAGC $\begin{array}{llllllllllllllllllll}S & E & A & Q & T & D & E & L & I & Q & V & I & S & L & F & Q & \text { W } & M & \text { L } & S\end{array}$

70

90

hadD stop 110

GGACTGGTTTTGAACGTCACACATTTCAAGCAGCAGGCGCTGAAAPACACTTCCAAAG CCTGACCAAAACTTGCAGTGTGTAAAGTTCGTCGTCCGCGACTTTATTCGTGAAGGTTTC $\begin{array}{lllllllllllllllll}G & \text { L } & \text { V } & \text { L } & \text { N } & \text { V } & \text { T } & \text { H } & \text { F } & \text { K } & Q & Q & \text { A } & \text { L } & \text { K } & \text { * }\end{array}$

S-D $\quad 130$ hed start $\quad 150 \quad 170$

GAAATAACCA ATGAAAAACATCCAAGGTATCGTTTTCGATTTGTATGGCACGCTCTACGA CTTTATTGGTTACTTTTTGTAGGTTCCATAGCAAAAGCTAAACATACCGTGCGAGATGCT $\begin{array}{lllllllllllllllll}M & K & N & I & Q & G & I & V & F & D & L & Y & G & T & L & Y & D\end{array}$

$190 \quad 210 \quad 230$

CGTGCATTCCGTGGTGCAAGCCTGTGAAGAGGTCTATCCGGGCCAAGGCGACGCTATTTC GCACGTAAGGCACCACGTTCGGACACTTCTCCAGATAGGCCCGGTTCCGCTGCGATAAAG $\begin{array}{lllllllllllllllllllll}V & H & S & V & V & Q & A & C & E & E & V & Y & P & G & Q & G & D & A & I & S\end{array}$

$250 \quad 270 \quad 290$

TCGCCTCTGGCGGCAAAAGCAATTGGAATACACCTGGCTCAGGAGCCTCATGGGCCGTTA AGCGGAGACCGCCGTTTTCGTTAACCTTATGTGGACCGAGTCCTCGGAGTACCCGGCAAT $\begin{array}{llllllllllllllllllll}R & L & W & R & Q & K & Q & L & E & Y & T & W & L & R & S & L & M & G & R & Y\end{array}$

$310 \quad 330 \quad 350$

CGTGAACTTTGAGAAAGCAACAGAGGATGCCTTGCGCTTTACCTGCACGCATCTGGGCTT GCACTTGAAACTCTTTCGTTGTCTCCTACGGAACGCGAAATGGACGTGCGTAGACCCGAA $\begin{array}{llllllllllllllllllll}V & N & F & E & K & A & T & E & D & A & L & R & F & T & C & T & H & L & G & L\end{array}$

370

390

410

GTCGCTCGATGATGAAACCCACCAGCGCCTCAGTGATGCTTATTTGCACCTCACCCCTTA CAGCGAGCTACTACTTTGGGTGGTCGCGGAGTCACTACGAATAAACGTGGAGTGGGGAAT $\begin{array}{lllllllllllllllllllll}S & L & D & D & E & T & H & Q & R & L & S & D & A & Y & L & H & L & T & P & Y\end{array}$ 430 450 470 TGCCGATACAGCTGACGCCGTTCGCCGTTTGAAAGCTGCGGGCCTACCGCTAGGCATCAT ACGGCTATGTCGACTGCGGCAAGCGGCAAACTTTCGACGCCCGGATGGCGATCCGTAGTA $\begin{array}{lllllllllllllllllllll}A & D & T & A & D & A & V & R & R & \text { L } & K & A & A & G & \text { L } & \text { P } & \text { L } & G & \text { I } & I\end{array}$

$$
490 \quad 510 \quad 530
$$

TTCAAATGGTTCTCATTGCTCGATCGAGCAAGTCGTGACTAACTCTGAAATGAATTGGGC AAGTTT TACCAAGAGTAACGAGCTAGCTCGTTCAGCACTGATTGAGACTTTACTTAACCCG $\begin{array}{llllllllllllllllllll}S & N & G & S & H & C & S & I & E & Q & V & V & T & N & S & E & M & N & W & A\end{array}$

$$
550 \quad 570 \quad 590
$$

GTTCGATCAGCTGATCAGCGTCGAGGATGTGCAAGTGTTCAAACCTGATAGTCGCGTCTA CAAGCTAGTCGACTAGTCGCAGCTCCTACACGTTCACAAGTTTGGACTATCAGCGCAGAT $\begin{array}{llllllllllllllllllll}F & D & Q & L & I & S & V & E & D & V & Q & V & F & K & P & D & S & R & V & Y\end{array}$

TAGCCTTGCCGAGAAGCGCATGGGTTTTCCAAAGGAAAACATCCTCTTCGTTTCGTCAAA ATCGGAACGGCTCTTCGCGTACCCAAAAGGT TTCCTTTTGTAGGAGAAGCAAAGCAGTTT $\begin{array}{llllllllllllllllllll}S & L & A & E & K & R & M & G & F & P & K & E & N & I & L & F & V & S & S & N\end{array}$

$$
670 \quad 690 \quad 710
$$

CGCGTGGGATGCGAGTGCAGCCAGTAACTTTGGTTTCCCGGTTTGCTGGATCAATCGGCA GCGCACCCTACGCTCACGTCGGTCATTGAAACCAAAGGGCCAAACGACCTAGTTAGCCGT $\begin{array}{llllllllllllllllllll}A & W & D & A & S & A & A & S & N & F & G & F & P & V & C & W & I & N & R & Q\end{array}$

Fig. 3. Nucleotide sequence of hadL (continued on following page). 
730

750

770

GAACGGCGCGTTTGATGAGCTGGATGCAAAGCCGACACACGTCGTGCGTAATCTCGCCGA CTTGCCGCGCAAACTACTCGACCTACGTTTCGGCTGTGTGCAGCACGCATTAGAGCGGCT $\begin{array}{llllllllllllllllllll}N & G & A & F & D & E & L & D & A & K & P & T & H & V & V & R & N & L & A & E\end{array}$ 790 810 hadL stop

830

AATGTCGAACTGGCTGGTTAATTCGCTCGATIAATCCATTGCATCTGGATTGGGAGAATC TTACAGCTTGACCGACCAATTAAGCGAGCTAATTAGGTAACGTAGACCTAACCCTCTTAG $\begin{array}{lllllllllll}M & S & N & W & L & V & N & S & L & D & *\end{array}$

$\begin{array}{ccc}850 & \text { Soll } 870 & 890 \\ \text { GTCCGCTCAGGGTGAAATCGCGCCGCGGTTTTCCCTGGCGGACATTAGAGCGGAAGATAA }\end{array}$ CAGGCGAGTCCCACTTTAGCGCGGCGCCAAAAGGGACCGCCTGTAATCTCGCCTTCTATT

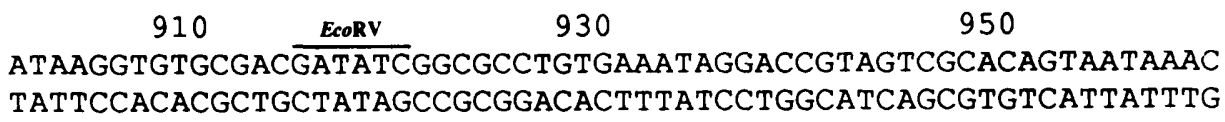

970

990

1010

TCAAGTATCCGTGGTTATTTTATGTACGGTTACCTTTCCCGACTTTCATTTGGGCGGGCC AGTTCATAGGCACCAATAAAATACATGCCAATGGAAAGGGCTGAAAGTAAACCCGCCCGG

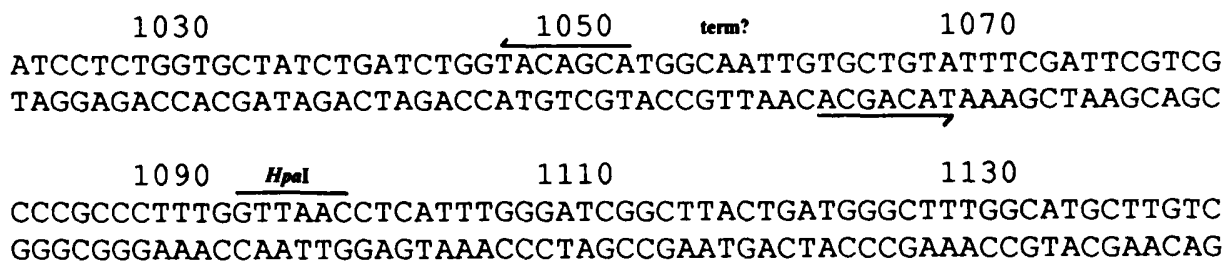

Fig. 3. Nucleotide sequence of hadL. The stop codon of hadD at position 106 is boxed, as are the start and stop codons of hadL (positions 131 and 812). The ribosome-binding site for hadL is underlined and the inverted repeat region which is proposed to be the transcriptional terminator downstream of hadL is indicated.

terminator, showing hadD and hadL to be the last two genes in an operon.

\section{Amino acid sequence of HadL}

The amino acid sequence of HadL shows that it is composed of subunits of $M_{\mathrm{r}} 25686$, closely matching the estimate of $M_{\mathrm{r}} 26000$ from SDS-PAGE analysis of the protein. It has a deduced isoelectric point of 5.0.

Comparison of the amino acid sequence of $\mathrm{HadD}$ and HadL shows no homology between the proteins, indicating different ancestral origins. However, the sequence of $\mathrm{HadL}$ is highly homologous to two L-haloalkanoic acid dehalogenases of Pseudomonas sp. strain CBS3 (Schneider et al., 1991). These proteins, DehcI and DehcII, show $38 \%$ and $51 \%$ amino acid identity respectively to $\mathrm{HadL}$, and show $38 \%$ identity between themselves (Fig. 4). The proteins are also almost identical in length. The highest homologies appear to fall in three regions of the proteins, indicated in Fig. 4 . The first region is the $\mathrm{N}$-terminal domain, in which all three proteins have a number of hydrophobic residues. The second and third regions of higher conservation show a number of conserved residues between all three proteins, with relatively high numbers of absolutely conserved Trp, Phe, Tyr and Gln residues. DehcI has also been purified (Klages et al., 1983), and this will be referred to in the Discussion. HadL appears to show no homology to any other protein in the GenEMBL database.

\section{Biochemical characteristics of HadL}

The enzyme activity of the fraction II preparation was measured at a range of $\mathrm{pH}$ values in $1 \mathrm{M}$-potassium phosphate buffer $(\mathrm{pH} \mathrm{7.0-8.0)}$ or in $1 \mathrm{M}$-glycine $/ \mathrm{NaOH}$ buffer ( $\mathrm{pH} 9 \cdot 0-11 \cdot 0)$. The optimum $\mathrm{pH}$ appeared to lie between 10 and 11; chloride release from MCPA was approximately fivefold greater at $\mathrm{pH} 10 \cdot 0$ than at $\mathrm{pH} 7 \cdot 0$. At $\mathrm{pH} 9.0$, chloride was released at approximately $1 \mu \mathrm{mol} \mathrm{min}^{-1}$ (mg protein) $)^{-1}$.

The activity of HadL against 2,3-dichloropropionate (DCPA), 2-monochlorobutyrate (MCBA), 2,3-dibromopropionate (DBPA) and 2-monobromobutyrate (MBBA) was also determined in the same buffers. At pH 9.0, 


\begin{tabular}{|c|c|c|c|c|c|}
\hline \multirow[b]{2}{*}{ DehcI } & \multicolumn{3}{|l|}{0} & \multicolumn{2}{|c|}{ म 49} \\
\hline & VDP IRACVFD & AYGTLLDVNT & $\overrightarrow{A V M K H A H D I G}$ & GCAEELSSLW & RQRQLEYSWT \\
\hline & $.1 \cdot 111$ & $\| 11 \mid 1$. & 1 & $1 \ldots .111$ & $\mid 1.11111$ \\
\hline HadL & MKNIQGIVFD & LYGTLYDVHS & VVQACEEVYP & GQGDAISRLW & RQKQLEYTWL \\
\hline & 1.11 .111 & 11111.1111 & $111 . .1$ & $\begin{array}{lll}1 & 11 & .1\end{array}$ & 111111111 \\
\hline DehcII & MQE IRGVVFD & LYGTLCDVHS & VAQLCGQYFP & ERGTEISLMW & RQKQLEYSWL \\
\hline & 50 & & & & $\begin{array}{r}99 \\
\end{array}$ \\
\hline DehcI & RTLMGRYADF & WQLTTEALDF & ALESFGLLER & TDLKNRLLDA & YHELSAYPDA \\
\hline & $1|1| 1 \mid .1$ & 1.111 & .11 & $\cdot \quad|1| 1 \mid$ & 11.1 .1 \\
\hline HadL & RSLMGRYVNF & EKATEDALRF & TCTHLGLSLD & DETHQRLSDA & YLHLTPYADT \\
\hline & 111111111 & 1111111 & $\begin{array}{llll}1 & 1 & 1 & 1\end{array}$ & $\ldots 1 . \quad 1 \ldots$ & $11 \ldots 11$. \\
\hline DehcII & RSLMGQYVSF & PQATEDALVF & VCNALNLKLR & EDTRIALCNE & YLNIKPYREV \\
\hline & 100 & & & & 149 \\
\hline DehcI & VGTLGALKAA & GFTTAILSNG & NNEMLRGALR & AGNLTEALDQ & CISVDEIKIY \\
\hline & $\cdot|1| 1$ & $1 . \quad .1 .111$ & & $\ldots 1.11$ & $111 \ldots \ldots$ \\
\hline HadL & ADAVRRLKAA & GLPLGIISNG & SHCSIEQVVT & NSEMNWAFDQ & LISVEDVQVF \\
\hline & 1. 1. & $\ldots 11.1 .111$ & 111.11 & $1 \quad \ldots \quad 1$. & $111 \ldots 11$ \\
\hline DehcII & RSALESLRSG & AVPLA ILSNG & SAHSIQSVVG & NAGIEHFFSH & LISADEVSVS \\
\hline & 150 & & & & 199 \\
\hline DehcI & KPDPRVYQFA & CDRLDVRPSE & VCEVSSNAWD & IGGAGAFGFN & TVRINRINKP \\
\hline & $111|1| 1 . .1$ & 1. & $\cdot|1| 1|1| 1 \mid$ & $\ldots 1 .|1|$ & $.11 \mid 1$. \\
\hline HadL & KPDSRVYSLA & EKRMGFPKEN & ILFVSSNAWD & ASAASNFGFP & VCWINRQNGA \\
\hline & $\begin{array}{lll}11 & 11\end{array}$ & 111. & .111111111 & 11.1 .111 & 111.11 \\
\hline DehcII & KPSPAAYELA & EKRLKVVRSK & LLFVSSNAWD & ASGARHFGFQ & VCWVNRSRNT \\
\hline & 200 & & & & \\
\hline DehcI & QEYSEAPQRH & QLSSISELPQ & LLLRLTQ* & 227 & \\
\hline & $\begin{array}{lll}- & 1\end{array}$ &.$\quad 11$. & $.1 \quad$. & & \\
\hline $\mathrm{HadL}$ & FDELDAKPTH & VVRNLAEMSN & WL. VNSLD* & 227 & \\
\hline & $1 \ldots 1 \quad .1$ & 1.11 .1 & .111 & & \\
\hline Dehcll & FEQLGERPDH & VISGLDELPN & LLNEASADR * & 229 & \\
\hline
\end{tabular}

Fig. 4. Amino acid sequence of HadL compared with DehcI and DehcII (Schneider et al., 1991). The three regions of highest homology are indicated.

MCBA and MBBA were degraded with approximately $75 \%$ of the efficiency that was observed for MCPA (calculated after correcting for spontaneous breakdown). At the same $\mathrm{pH}$ value, DCPA was degraded at approximately $30 \%$ of the efficiency of MCPA. DBPA was unstable at $\mathrm{pH} 9 \cdot 0$, but at lower $\mathrm{pH}$ values it was degraded at a similar rate to DCPA. No other chemicals were tested.

\section{Discussion}

Studies on dehalogenase enzymes able to dechlorinate 2-haloalkanoic acids have suggested that there are four different types of enzymes. Type 1 enzymes are specific only for L-haloacids, the reaction products are of an optical configuration opposite to that of the substrate
(Leigh et al., 1988) and the enzymes are insensitive to thiol-blocking agents (Little \& Williams, 1971). Type 2 enzymes dehalogenate both $\mathrm{D}$ - and L-haloacids, again invert the optical configurations of the products (Leigh $e t$ al., 1988) and are insensitive to thiol-blocking agents (Motosugi et al., 1982; Weightman et al., 1982). Type 3 enzymes again dehalogenate both $D$ - and L-haloacids, but the products are of the same optical configuration as the substrates and these enzymes are sensitive to thiolblocking agents (Weightman et al., 1982). Type 4 enzymes are specific for $D$-haloacids, inverting the optical configuration of the substrate (Leigh et al., 1988), and again are insensitive to thiol-blocking agents (Smith et al., 1990).

The enzyme described in this paper appears to be of the type 1 class. Other enzymes which appear to be of this type include those described by Goldman et al. (1968), 
Little \& Williams (1971), Klages et al. (1983), Leigh et al. (1988) and Tsang et al. (1988). The enzyme isolated from Pseudomonas sp. NCIB 9061 (Little \& Williams, 1971) was reported to have an $M_{\mathrm{r}}$ of 15000 . The enzymes isolated from $P$. cepacia MBA4 (Tsang et al., 1988) and Pseudomonas sp. CBS3 (DehcI; Klages et al., 1983) were reported to have $M_{\mathrm{r}}$ values of 23000 and 28000 respectively, closer to the $M_{\mathrm{r}}$ of 26000 seen for HadL upon SDS-PAGE analysis. However, both of these proteins were reported to exist as dimers, in contrast to HadL, which appears to be a tetramer. Dehalogenase enzymes have been grouped according to their relative electrophoretic mobilities (Tsang et al., 1988) so HadL may fall into a different group in this respect. The enzymes isolated from $P$. cepacia and Pseudomonas sp. CBS3 also have $\mathrm{pH}$ optima at approximately $9 \cdot 5$, slightly lower than that observed for HadL (although this could be an artefact of different assay and buffer conditions).

The enzyme from Pseudomonas sp. NCIB 9061 was little affected by a range of inhibitors, indicating that thiol and free amino groups, and Ser and Tyr residues, were unlikely to be involved in the active site of the enzyme (Little \& Williams, 1971). Since activity was lost upon oxidation and/or halogenation with iodine, which reacts primarily with the amino acid residues Trp, His, Tyr and Cys (with increasing efficiency), Little \& Williams (1971) suggested that His was the residue in the active site of the enzyme (although they did not rule out Trp). From the sequence data of $\mathrm{HadL}$ it can be seen that there are no His residues in the three regions of high homology to Dehcl and Dehcll. There is a conserved His at position 210, however, and DehclI and HadL share a conserved His in the first region of high identity. A number of Trp residues are also conserved between proteins in the regions of high identity.

It has also been suggested that the carboxy group of the acid substrate interacts with a basic group on the enzyme to bring about the correct steric conformation. HadL has a $\mathrm{pH}$ optimum of about 10.5 . Its primary substrate, MCPA, has a $\mathrm{pK}_{\mathrm{a}}$ of 2.83 so would be completely dissociated in this $\mathrm{pH}$ range, permitting interaction with a basic group. In the second region of high identity between DehcI, DehcII and HadL there are two absolutely conserved Arg residues ( $\mathrm{pK}_{\mathrm{a}}$ 12.48), and a third conserved Arg is found at position 195. One or more of these could be involved in the formation of a positively-charged pocket to which the carboxy group may bind. From these homologies it should be possible to study further the enzyme action and the mechanism of the reaction by mutation of the encoding DNA in these regions.

Since this paper was submitted for publication, a haloacid dehalogenase from Xanthobacter autotrophicus GJ10 has been characterized and the nucleotide sequence of the gene determined (van der Ploeg et al., 1991). This protein has a high degree of homology to HadL, DehcI and DehclI.

We are very grateful to David Porter and Ross Williams for help and advice on protein purification.

D.H.A.J. was supported by an SERC CASE studentship. The protein microsequencer used was purchased with an SERC equipment grant awarded to C.M.T. and three other staff in the Schools of Biological Sciences and Biochemistry. HPLC equipment was purchased with an MRC shared equipment grant to C.M.T.

\section{References}

BARTH, P. T., Bolton, L. \& Thomson, J. C. (1992). Cloning and partial sequencing of an operon encoding 2-haloalkanoate dehalogenases of opposite stereospecificity from Pseudomonas putida. Journal of Bacteriology 174 (in the Press).

BIRNBoIm, H. C. \& DOLY, J. (1979). A rapid alkaline extraction procedure for screening recombinant plasmid DNA. Nucleic Acids Research 7, 1513-1523.

Chaudhry, G. R. \& Chapalamadugu, S. (1991). Biodegradation of halogenated organic compounds. Microbiological Reviews 55, 59-79.

DevereuX, J., Haeberli, P. \& Smithies, O. (1984). A comprehensive set of sequence analysis programs for the VAX. Nucleic Acids Research 12, 387-395.

Ghosal, J.-S., You, I. S., Chatterjee, D. K. \& Chakrabarty, A. M. (1985). Microbial degradation of halogenated compounds. Science 228, 135-142.

Goldman, P., Milne, G. W. A. \& Keister, D. B. (1968). Carbonhalogen bond cleavage. III. Studies on bacterial halidohydrolases. Journal of Biological Chemistry 243, 428-434.

HARDMAN, D. J. \& Slater, J. H. (1981). Dehalogenases in soil bacteria. Journal of General Microbiology 123, 117-128.

Jagura-Burdzy, G., Ibbotson, J. P. \& Thomas, C. M. (1991). The kor $F$ region of broad-host-range plasmid $\mathrm{RK} 2$ encodes two polypeptides with transcriptional repressor activity. Journal of Bacteriology 173, 826-833.

Janssen, D. B., Pries, F., Van der Ploeg, J., Kazemier, B., Terpstra, P. \& WithOLT, B. (1989). Cloning of 1,2-dichloroethane degradation genes of Xanthobacter autotrophicus GJ10 and expression and sequencing of the dhlA gene. Journal of Bacteriology 171, 679l-6799.

Klages, U., KRAUSS, S. \& LingenS, F. (1983). 2-Haloacid dehalogenase from a 4-chlorobenzoate-degrading Pseudomonas spec. CBS3. Hoppe-Seyler's Zeitschrift für Physiologische Chemie 364, 529-535.

LA Roche, S. D. \& LeISINGER, T. (1990). Sequence analysis and expression of the bacterial dichloromethane dehalogenase structural gene, a member of the glutathione $S$-transferase supergene family. Journal of Bacteriology 172, 164-171.

LAEMMLI, U. K. (1970). Cleavage of structural proteins during the assembly of the head of bacteriophage T4. Nature, London 227, 680-685.

Leigh, J. A., Skinner, A. J. \& CoOper, R. A. (1988). Partial purification, stereospecificity and stoichiometry of three dehalogenases from a Rhizobium species. FEMS Microbiology Letters 49. 353-356.

LitTle, M. \& Williams, P. A. (1971). A bacterial halidohydrolase. European Journal of Biochemistry 21, 99-109.

Motosugi, K., Esaki, N. \& Soda, K. (1982). Purification and properties of a new enzyme, DL-2-haloacid dehalogenase, from Pseudomonas sp. Journal of Bacteriology 150, 522-527.

Noll, F. (1984). Metabolites. 1. Carbohydrates. In Methods of Enzymatic Analysis, vol. 6, pp. 582-588. Edited by H. U. Bergmeyer. Weinheim, FRG: Verlag Chemie.

NORMORE, M. W. (1976). Guanine-plus-cytosine (GC) composition of the DNA of bacteria, fungi, algae and protozoa. In Handbook of Biochemistry and Molecular Biology, pp. 65-240. Edited by G. D. Fasman. Cleveland, OH: CRC Press. 
Platt, T. (1986). Transcription termination and the regulation of gene expression. Annual Review of Biochemistry 55, 339-372.

van der Ploeg, J., van Hall, G. \& Janssen, D. B. (1991). Characterization of the haloacid dehalogenase from Xanthobacter autotrophicus GJ10 and sequencing of the dhlB gene. Journal of Bacteriology 173, 7925-7933.

Sambrook, J., Fritsch, E. F. \& Maniatis, T. (1989). Molecular Cloning: a Laboratory Manual, 2nd edn. Cold Spring Harbor, NY: Cold Spring Harbor Laboratory.

Sanger, F., Nicklen, S. \& Coulsen, A. R. (1977). DNA sequencing with chain-terminating inhibitors. Proceedings of the National Academy of Sciences of the United States of America 74, 5463-5467.

SChNeider, B., Muller, R., Frank, R. \& Lingens, F. (1991). Complete nucleotide sequences and comparison of the structural genes of two 2-haloalkanoic acid dehalogenases from Pseudomonas sp. strain CBS3. Journal of Bacteriology 173, 1530-1535.

Slater, J. H., Lovatt, D., Weightman, A. J., Senior, E. \& Bull, A. T. (1979). The growth of Pseudomonas putida on chlorinated aliphatic acids and its dehalogenase activity. Journal of General Microbiology 114, 125-136.
Smith, J. M., Harrison, K. \& Colby, J. (1990). Purification and characterization of D-2-haloacid dehalogenase from Pseudomonas putida strain AJ1/23. Journal of General Microbiology 136, 881886.

Tsang, J. S. H., Sallis, P. J., Bull, A. T. \& Hardman, D. J. (1988). A monobromoacetate dehalogenase from Pseudomonas cepacia MBA4. Archives of Microbiology 150, 441-446.

WaDa, K., Wada, Y., DoI, H., Ishibashi, F., Gojobori, T. \& IKemura, T. (1991). Codon usage tabulated from the Genbank genetic sequence data. Nucleic Acids Research 19, 1981-1986.

Weightman, A. J., Weightman, A. L. \& Slater, J. H. (1982). Stereospecificity of 2-monochloropropionate dehalogenation by the two dehalogenases of Pseudomonas putida PP3: evidence for two different dehalogenation mechanisms. Journal of General Microbiology 128, 1755-1762.

Yanisch-Perron, C., Vieira, J. \& Messing, J. (1985). Improved M13 phage cloning vectors and host strains: nucleotide sequences of the M13mp18 and pUC19 vectors. Gene 33, 103-119. 